\title{
Multiclawed $\mathrm{SiO}_{2}$ Nano-Antibacterial Agent Based on Charge Inversed Ce6 Ionic Liquid Polymers for Combating Oral Biofilm Infection
}

\author{
Ziyi Jiao, ${ }^{1}$ Yonggang Teng, ${ }^{2}$ Chunjing Zhan, ${ }^{1}$ Youbei Qiao, ${ }^{1}$ Yuying Ma, ${ }^{3}$ Chaoli Wang $\left(\mathbb{D},{ }^{1}\right.$ \\ and Hong $\mathrm{Wu} \mathbb{1}^{1}$ \\ ${ }^{1}$ Department of Pharmacy, Air Force Medical University, Xi'an 710032, China \\ ${ }^{2}$ Department of Thoracic Surgery, The Second Affiliated Hospital of AFMU, Xi'an, China \\ ${ }^{3}$ Department of Pharmacy, Shaanxi University of Chinese Medicine, Xianyang 712046, China
}

Correspondence should be addressed to Chaoli Wang; wangchaoli2012@163.com and Hong Wu; wuhong@fmmu.edu.cn

Ziyi Jiao and Yonggang Teng contributed equally to this work.

Received 10 August 2021; Accepted 20 November 2021; Published 12 January 2022

Academic Editor: Iaroslav Gnilitskyi

Copyright (C) 2022 Ziyi Jiao et al. This is an open access article distributed under the Creative Commons Attribution License, which permits unrestricted use, distribution, and reproduction in any medium, provided the original work is properly cited.

\begin{abstract}
Photodynamic antimicrobial chemotherapy (PACT) is a promising therapy against biofilm infection. However, due to the saliva clearance and obstacle of biofilm, the photosensitizer is difficult to concentrate in the infection site; then, the PACT is less effective on oral biofilm infection. In this article, we report a special nano-antibacterial agent $\left(\mathrm{SiO}_{2}-\mathrm{P}_{\mathrm{Ce} \text {-IL }}\right)$ to solve the bottleneck problem of PACT in treatment of oral biofilm infections. The $\mathrm{SiO}_{2}-\mathrm{P}_{\mathrm{Ce}-\mathrm{IL}}$ was composed of $\mathrm{SiO}_{2}$ and poly ionic liquid photosensitizer $\left(\mathrm{P}_{\text {Ce6-IL }}\right)$ and had tri-fold features of eliminate biofilm infection: high binding ability, breaking biofilm barriers, and enrichment photosensitizer in infection site. In oral biofilm, the $\mathrm{SiO}_{2}-\mathrm{P}_{\mathrm{Ce}-\mathrm{IL}}$ changed to $\mathrm{SiO}_{2}-\mathrm{P}_{\mathrm{IL}}{ }^{+}$like claws of octopus that could hold tightly with biofilm. Then, the poly-dodecyl on the $\mathrm{SiO}_{2}-\mathrm{P}_{\mathrm{IL}}^{+}$broke down the barrier of biofilm. The results of HR-MS and zeta potential indicated that $\mathrm{SiO}_{2}-\mathrm{P}_{\mathrm{Ce} \text { - IL }}$ could change to positive $\left(\mathrm{SiO}_{2}-\mathrm{P}_{\mathrm{IL}}{ }^{+}\right)$in acidic environment. The interaction forces and morphology results proved that the $\mathrm{SiO}_{2}-\mathrm{P}_{\mathrm{IL}}{ }^{+}$had a higher affinity to biofilm and could destroy the biofilm structure. Then, the photosensitizer was enriched in biofilm at sites of infection. The in vitro and in vivo experiments showed that $\mathrm{SiO}_{2}-$ $\mathrm{P}_{\text {Ce6-IL }}$ could effectively eradicate oral biofilm infections and control of dental caries.
\end{abstract}

\section{Introduction}

Oral biofilm infection is most important pathogenic factor of dental caries $[1,2]$. Thus, eliminating biofilm on the tooth surface is a primary strategy to prevent and treat dental caries [3]. However, with the protection, bacteria in the biofilm is difficult to eradicate by common strategy of mechanical cleaning combined antibiotics. In this background, it is urgently to develop new treatment against oral biofilm infection. One promising therapy is PACT [4]. Compared with traditional treatment, PACT could efficiently control of bacteria and bacterial biofilm infection. However, owing to rapid clearance by saliva and barrier of biofilm, the photosensitizers are not concentrated in the infection site, and the efficacy of PACT against oral biofilm infections is limited [5]. Faced with the dilemma, the concentration of photosensitizer in the site of oral biofilm is the key to improve the PACT efficiency.

An understanding of oral biofilms matrix could offer opportunities to exploit photosensitizer delivery systems [6]. Because oral biofilm develop when microbes accumulate and form structured communities encapsulated within an extracellular matrix such as exopolysaccharides (EPS) [7, $8]$, the sugars are fermented by bacteria within the EPS matrix, then created highly acidic microenvironments and negative charge. The $\mathrm{pH}$ values often reach $\mathrm{pH} 4.5$ or even lower in oral biofilm and particularly after exposure to sucrose, starch, and other cariogenic food products [9]. So, 


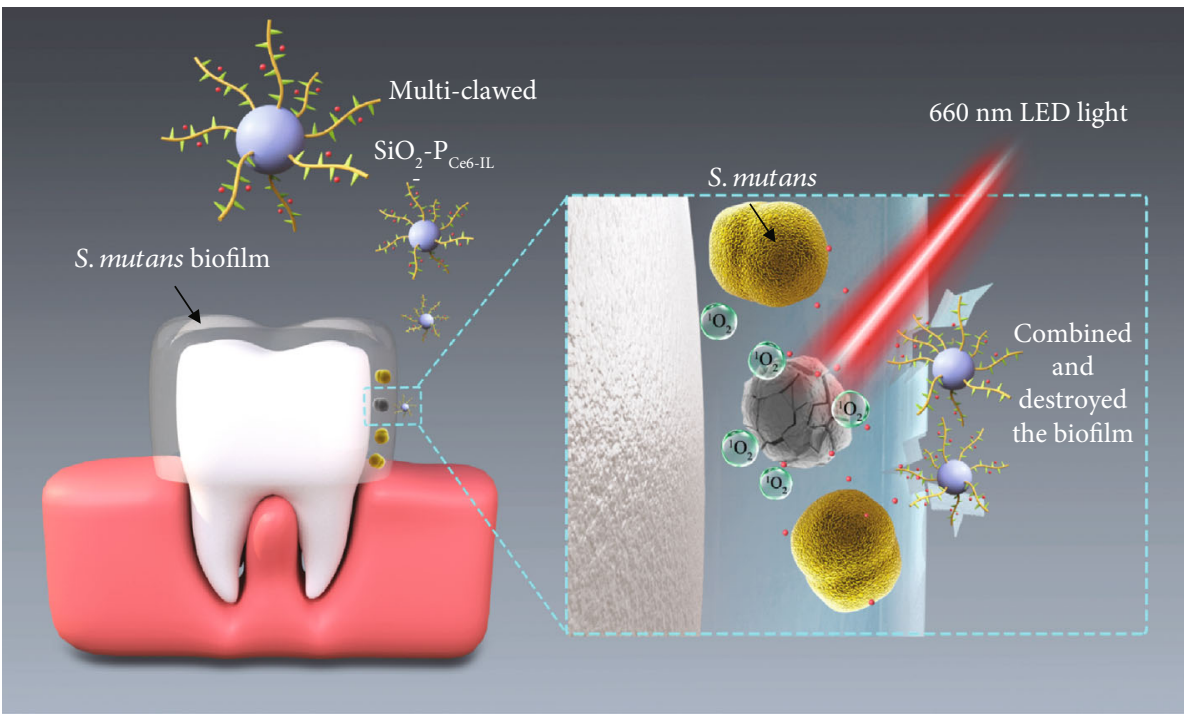

Figure 1: The mechanism of multiclawed $\mathrm{SiO}_{2}-\mathrm{P}_{\mathrm{Ce}-\mathrm{IL}}$ against oral biofilm.

photosensitizer delivery system that could response to lower $\mathrm{pH}$ microenvironments is an effective method to improve delivery efficiency. Furthermore, many researches on cationic polymers [10], especially on the charge-reversal polymers, indicated that positively charged polymers could combine with extracellular polymeric substances (EPS) [11] and increase concentration of photosensitizer in biofilm. However, due to the dense and thick structure of biofilm, the photosensitizers difficultly penetrated into biofilm; then, photochemical reaction initiated by photosensitizer occurs mainly in the outermost layers of biofilm. The PACT efficiency was not significantly improved.

To overcome these challenges, polyionic liquid that composed of polycation and anion is introduced in previous studies $[12,13]$. Inspired by octopus claws, the polyionic liquid photosensitizer nanoparticle $\left(\mathrm{SiO}_{2}-\mathrm{P}_{\mathrm{Ce}-\mathrm{IL}}\right)$ like arms of octopus was prepared in this work. In acid microenvironment of oral biofilm, the $\mathrm{SiO}_{2}-\mathrm{P}_{\mathrm{Ce}-\mathrm{IL}}$ could change to nanoclaws $\mathrm{SiO}_{2}-\mathrm{P}_{\mathrm{IL}}{ }^{+}$and firmly combine to negatively charged EPS to overcome the saliva cleaning. Then, the dodecyl on the $\mathrm{SiO}_{2}-\mathrm{P}_{\mathrm{IL}}{ }^{+}$could pierce through the biofilm and break down the barrier of biofilm. Finally, the photosensitizer was highly concentrated in oral biofilm, and the biofilm infection was eliminated. The high binding energy between positively charged $\mathrm{SiO}_{2}-\mathrm{P}_{\mathrm{Ce} \text {-IL }}$ and oral biofilm, excellent breaking ability of polydodecyl, and effective enrichment of photosensitizer were the key factors to effectively eliminate oral biofilm. The mechanism of $\mathrm{SiO}_{2}-\mathrm{P}_{\mathrm{Ce} 6-\mathrm{IL}}$ against oral biofilm is showed in Figure 1.

\section{Materials and Methods}

2.1. Materials. Ce6 was purchased from Frontier Scientific. $\mathrm{KOH}$, methanol, methanol, absolute ethanol, cyclohexane, ammonia solution, hexanol, trimethylamine, Triton $\mathrm{x}-100$, and 1,3-diphenylisobenzofuran (DPBF) were purchased from Sinopharm Chemical Reagent Co., Ltd. Artificial saliva was purchased from Beijing Regan Biotechnology Co., Ltd.
Tetraethyl orthosilicate (TEOS), 3-aminopropyl triethoxysilane (APTES), $\mathrm{CuCl}, 2$-bromoisobutyryl bromide, and $\mathrm{N}, \mathrm{N}, \mathrm{N}^{\prime}, \mathrm{N}^{\prime \prime}, \mathrm{N}^{\prime \prime}$-pentamethyldiethylenetriamine were purchased from Aladdin. Streptococcus mutans (S. mutans, ATCC 700610) was purchased from ATCC. Brain Heart Infusion Broth (BHIB) was purchased from Beijing Land Bridge Technology Co., Ltd. The live/dead Baclight bacterial viability kit (L7012) was purchased from Invitrogen. Hydroxyapatite tablets were purchased from National Biomedical Materials Engineering Technology Research Center (China). Alexa Fluor 647 was purchased from Thermo Fisher Scientific.

2.2. The Synthesis and Characterization of Multiclawed $\mathrm{SiO}_{2}$ $P_{\text {Ce6-IL }}$. The preparation of $\mathrm{SiO}_{2}-\mathrm{Br}$ was similar with previous research [14], except the $2.4 \mathrm{~mL}$ of triethylamine and 2-bromoisobutyryl bromide $(1.2 \mathrm{~mL})$ were added to prepare $\mathrm{SiO}_{2}$-Br. The multiclawed $\mathrm{SiO}_{2}-\mathrm{P}_{\mathrm{Ce}}$-IL was prepared by ATRP. Briefly, $10 \mathrm{mg}$ Ce6-IL and $\mathrm{SiO}_{2}-\mathrm{Br}$ dispersed into a mixture solution of ethanol and distilled water $(5: 1, V: V)$ for stirring $10 \mathrm{~min}$ at $800 \mathrm{rpm} .200 \mu \mathrm{L}$ of PMDETA and $30 \mathrm{mg}$ of $\mathrm{CuCl}$ were quickly transferred into the flask for reaction $8 \mathrm{~h}$ at $35^{\circ} \mathrm{C}$. The $\mathrm{SiO}_{2}-\mathrm{P}_{\mathrm{Ce} 6-\mathrm{IL}}$ was washed with ethanol, distilled water.

The morphology of $\mathrm{SiO}_{2}-\mathrm{P}_{\mathrm{Ce}-\mathrm{IL}}$ was examined by TEM and SEM. The change of $\mathrm{SiO}_{2}-\mathrm{P}_{\mathrm{Ce}-\mathrm{IL}}$ zeta potentials in $\mathrm{pH} 4.5$ and 7.4 was measured by a Delsa Nano C particle analyzer (Beckman Coulter Ireland Inc.).

The UV absorption of $5.0 \mathrm{mg} \cdot \mathrm{mL}^{-1} \mathrm{SiO}_{2}-\mathrm{P}_{\mathrm{Ce}-\mathrm{IL}}$ was measured by UV-vis (MAPADA). The Ce6 loading efficiency $(L)$ was calculated as formula:

$$
L=\frac{C \times V}{W} \times 100 \%
$$

$L$ was $\mathrm{SiO}_{2}-\mathrm{P}_{\mathrm{Ce}-\mathrm{IL}}$ loading efficiency; $C$ was the concentration of $\mathrm{Ce} 6\left(\mathrm{mg} \cdot \mathrm{mL}^{-1}\right) ; V$ was solution volume $(\mathrm{mL}) ; W$ was the weight of $\mathrm{SiO}_{2}-\mathrm{P}_{\mathrm{Ce}-\mathrm{IL}}(\mathrm{mg})$. 

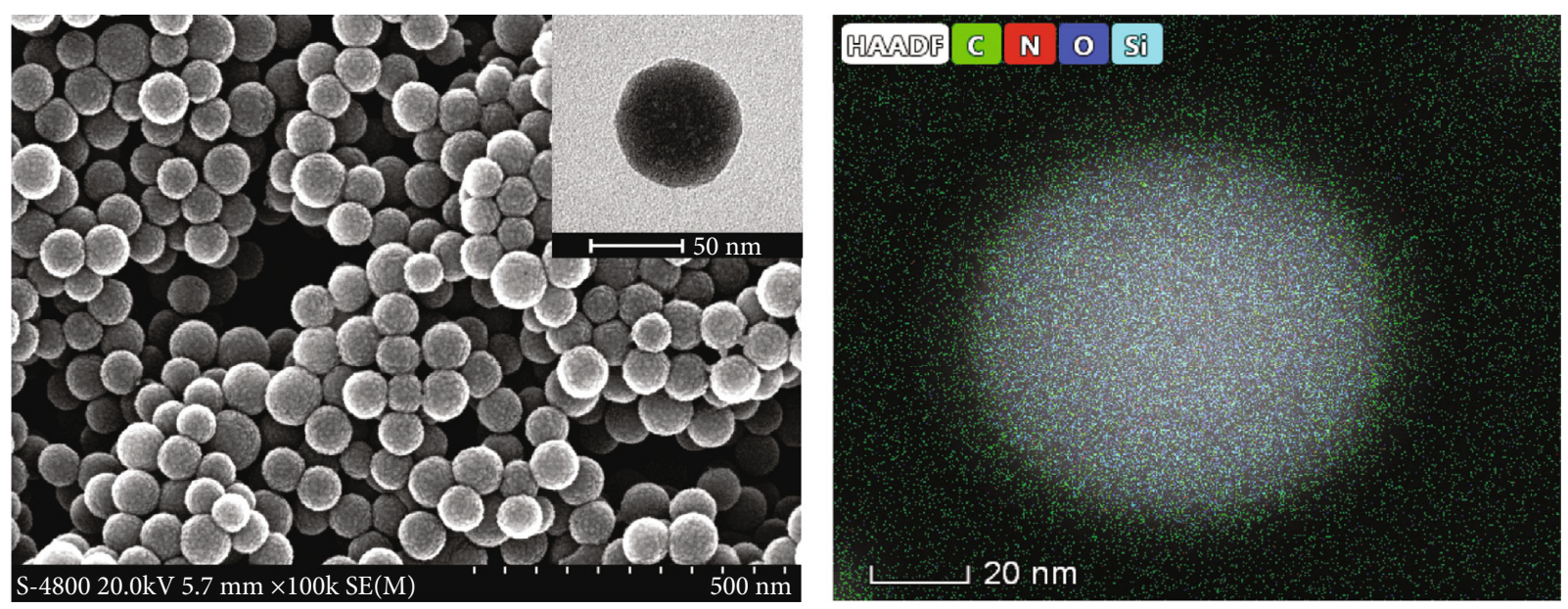

(a)
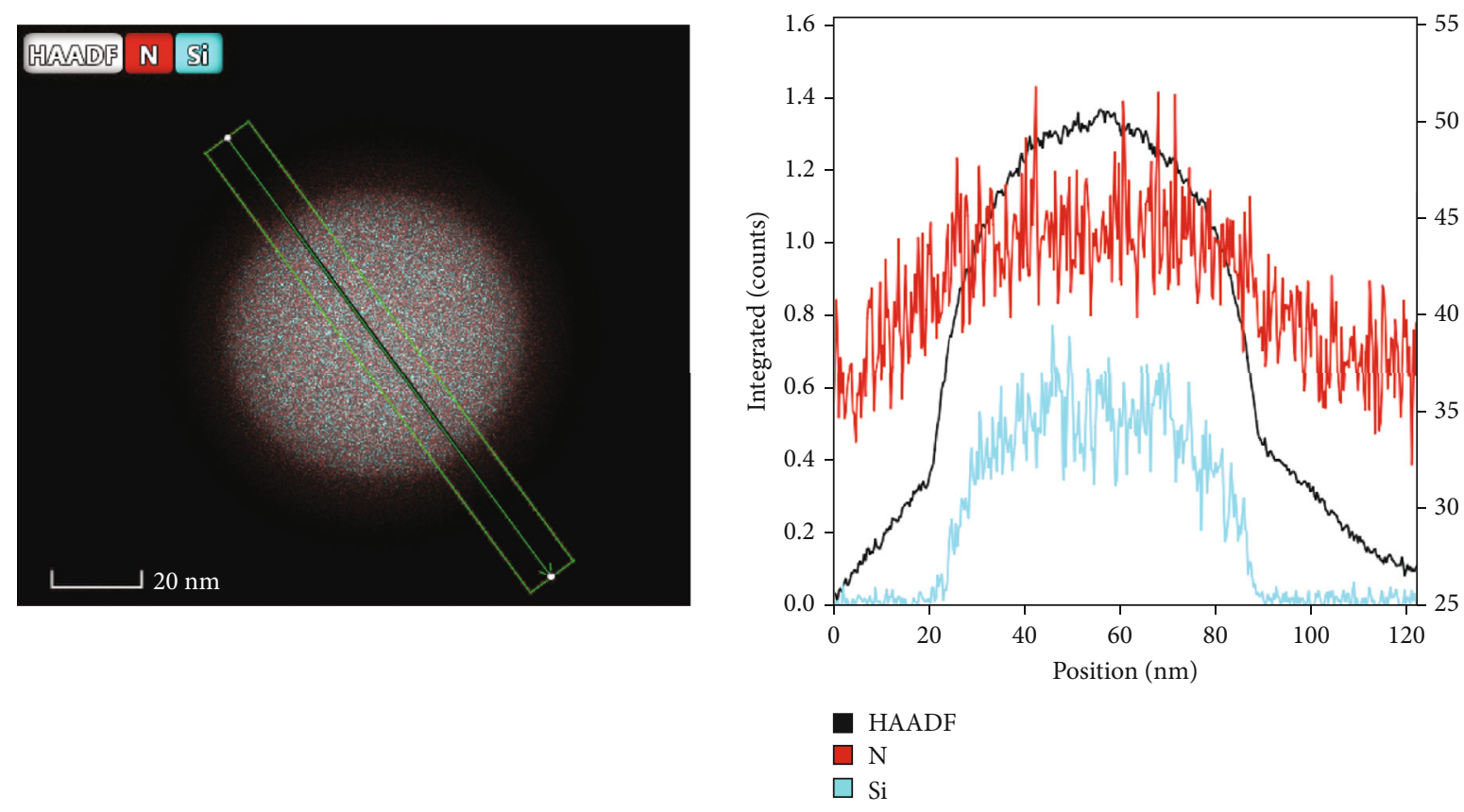

(b)

Figure 2: Continued. 


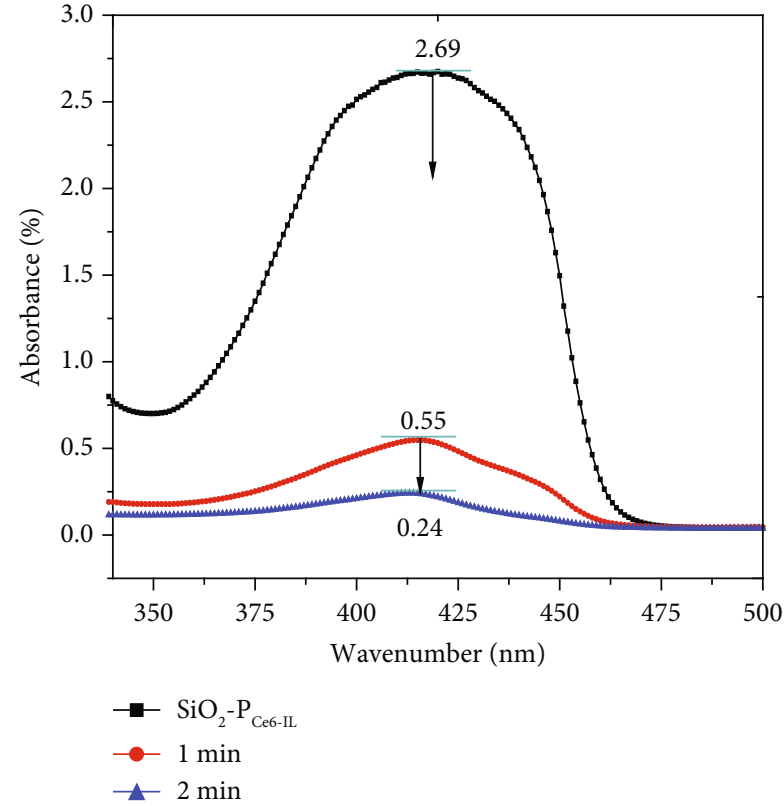

(c)

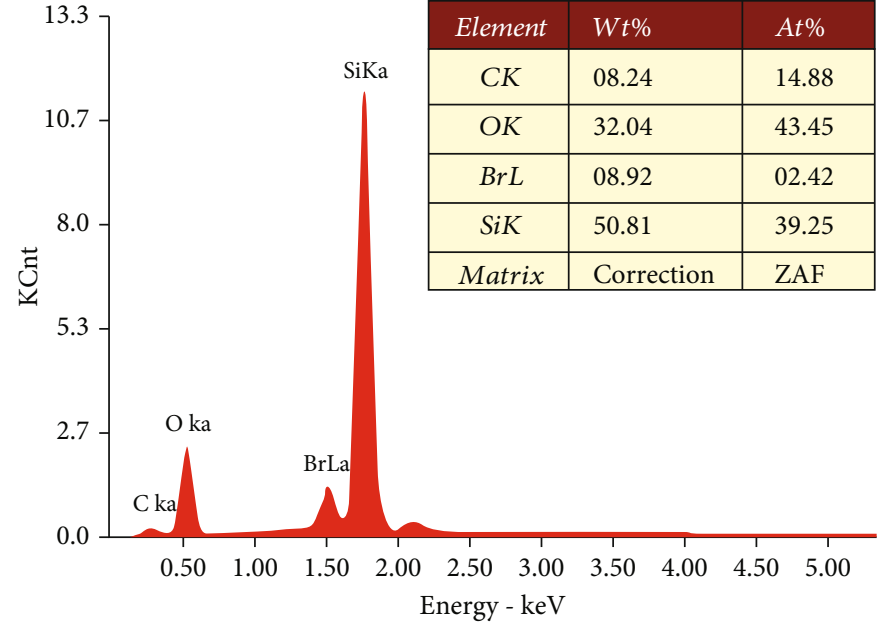

(d)

Figure 2: Characterization of $\mathrm{SiO}_{2}-\mathrm{P}_{\mathrm{Ce}-\mathrm{IL}}$ : (a) the SEM and TEM of $\mathrm{SiO}_{2}-\mathrm{P}_{\mathrm{Ce}-\mathrm{IL}}$; (b) the distribution of $\mathrm{Si}$ and $\mathrm{N}$ of $\mathrm{SiO}_{2}-\mathrm{P}_{\mathrm{Ce} 6-\mathrm{IL}}$; (c) the ${ }^{1} \mathrm{O}_{2}$ concentration of $\mathrm{SiO}_{2}-\mathrm{P}_{\mathrm{Ce}-\mathrm{IL}}$; (d) the element analysis of $\mathrm{SiO}_{2}-\mathrm{Br}$ by EDS.

The Ce6 released in acidic microenvironment of oral biofilm ( $\mathrm{pH} 4.5$ ) was quantified by UV-vis. Briefly, $10 \mathrm{mg}$ multiclawed $\mathrm{SiO}_{2}-\mathrm{P}_{\mathrm{Ce} \text {-IL }}$ was placed in $\mathrm{pH} 4.5$ solution $10 \mathrm{~min}$ and separated by centrifugation. The concentration of Ce6 in supernatant was examined by UV-vis.

DPBF was used to measure the generation of ${ }^{1} \mathrm{O}_{2}$ [15]. Briefly, $2.0 \mathrm{~mL}$ DMSO solution containing $\mathrm{SiO}_{2}-\mathrm{P}_{\mathrm{Ce}-\mathrm{IL}}$ (equalled $100 \mu \mathrm{M}$ Ce6) and $100 \mu \mathrm{M}$ DPBF was irradiated by $660 \mathrm{~nm}$ light with a power density of $0.5 \mathrm{~W} \cdot \mathrm{cm}^{-2}$. The absorbance of DPBF at about $410 \mathrm{~nm}$ was taken to record at 1 and $2 \mathrm{~min}$.

2.3. Binding Ability of $\mathrm{SiO}_{2}-P_{\text {Ce6-IL }}$ to Oral Biofilm. Hydroxyapatite tablets $(6.0 \mathrm{~mm}$ in diameter, $1.5 \mathrm{~mm}$ in thickness) were washed twice with PBS and incubated with artificial saliva to obtain saliva-coated hydroxyapatite. The S. mutans biofilm was formed on hydroxyapatite surfaces in BHIB medium which contained S. mutans $\left(10^{6}\right)$ and $2 \%$ sucrose $(w / v)$ for incubated $72 \mathrm{~h}$ at $37^{\circ} \mathrm{C}$.

The binding capacity of $\mathrm{SiO}_{2}-\mathrm{P}_{\mathrm{Ce}-\mathrm{IL}}$ to the hydroxyapatite and S. mutans biofilm was measured by UV-vis. The $0.1 \mathrm{mM}$ multiclawed $\mathrm{SiO}_{2}-\mathrm{P}_{\mathrm{Ce}-\mathrm{IL}}$ was incubated with hydroxyapatite and biofilm in $\mathrm{pH} 4.5$ and 7.4 solutions for $10 \mathrm{~min}$ at $37^{\circ} \mathrm{C}$, and then, the concentration of $\mathrm{SiO}_{2}-\mathrm{P}_{\mathrm{Ce}-\mathrm{IL}}$ was measured before and after adsorption to calculated binding capacity.

In order to examine the binding ability of $\mathrm{SiO}_{2}-\mathrm{P}_{\mathrm{Ce}-\mathrm{IL}}$ to oral biofilm, the interaction between $\mathrm{SiO}_{2}-\mathrm{P}_{\mathrm{Ce}-\mathrm{IL}}$ with $\mathrm{S}$. mutans biofilm was measured by AFM. The procedure was as follows: the AFM tip (NP-O10, Bruker) contacted with epoxy. After waiting for $10 \mathrm{~min}, 1 \mu \mathrm{L} \mathrm{SiO}{ }_{2}-\mathrm{P}_{\mathrm{Ce}-\mathrm{IL}}(0.1 \mathrm{mM})$ was put on the tip and heated to completely cure epoxy. Then, the AFM tip was put in ultrapure water and ultrasoni- cated for $30 \mathrm{~s}$ to get rid of unattached $\mathrm{SiO}_{2}-\mathrm{P}_{\mathrm{Ce}-\mathrm{IL}}$. The SEM was used to check the AFM tip modified with $\mathrm{SiO}_{2}-\mathrm{P}_{\mathrm{Ce}-\mathrm{IL}}$.

2.4. Photosensitizer Concentration in Biofilm. The S. mutans biofilm was stained with Alexa Fluor 647. Briefly, $1 \mu \mathrm{M}$ Alexa Fluor 647 was added to the S. mutans biofilms for 6h. $20 \mu \mathrm{L}$ of $\mathrm{SiO}_{2}-\mathrm{P}_{\mathrm{Ce}-\mathrm{IL}}$ or $\mathrm{Ce} 6(120 \mu \mathrm{M})$ was added onto the S. mutans biofilm interaction for $30 \mathrm{~min}$, and then, wash with $\mathrm{PBS} 3$ times to remove unconjugated $\mathrm{SiO}_{2}-\mathrm{P}_{\mathrm{Ce}-\mathrm{IL}}$ or Ce6. The laser scanning confocal microscopy (LSCM, Leica TCS SP8 STED 3X Super-resolution Confocal Microscope, Germany) was used to examine the concentration of Ce6 in biofilm.

2.5. Antibiofilm Activity. The S. mutans biofilm was treated with $\mathrm{PBS}, \mathrm{SiO}_{2}-\mathrm{P}_{\mathrm{Ce}}$-IL, and $\mathrm{Ce} 6$. The biofilm incubated with BacLight live/dead dye in the dark after illumination for 15 min to observe dead/live bacteria. The CLSM images were taken to analyze the live and dead bacteria.

2.6. In Vivo Efficacy. Animal experiments were performed on a well-established model of dental caries disease as described in previous literatures [16]. Briefly, rats with two weeks old were purchased from animal center of the Air Force Medical University and screened for infection with S. mutans. Any rats infected with S. mutans prior to inoculation were removed. The animals were infected orally using an actively growing culture of S. mutans by oral swabbing three times a day for 2 weeks. Infected animals were randomly placed into three treatment groups of $n=5$, and their teeth treated topically once daily. The treatment groups included (1) PBS, (2) $\mathrm{SiO}_{2}-\mathrm{P}_{\mathrm{Ce} \text {-IL }}$ (amount to $0.1 \mathrm{mM} \mathrm{Ce6)}$ using a $660 \mathrm{~nm}$ LED light $\left(0.5 \mathrm{~W} / \mathrm{cm}^{2}\right)$ for $15 \mathrm{~min}$, and (3) 


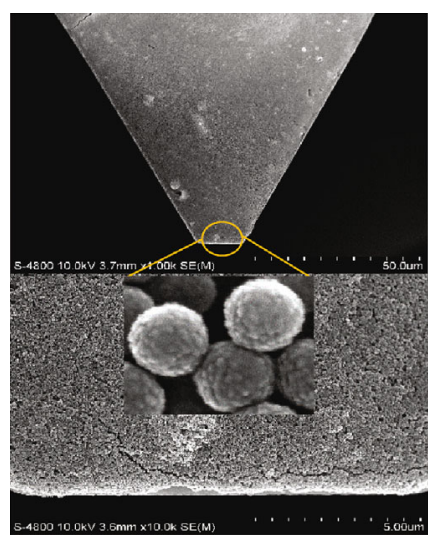

(a)

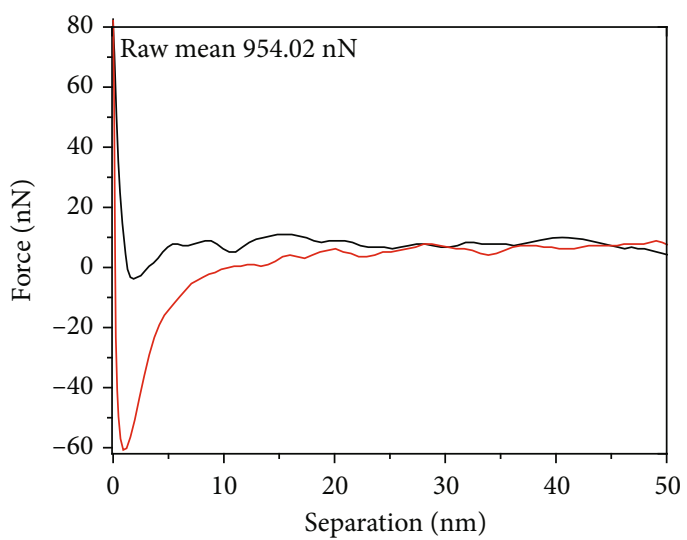

(c)

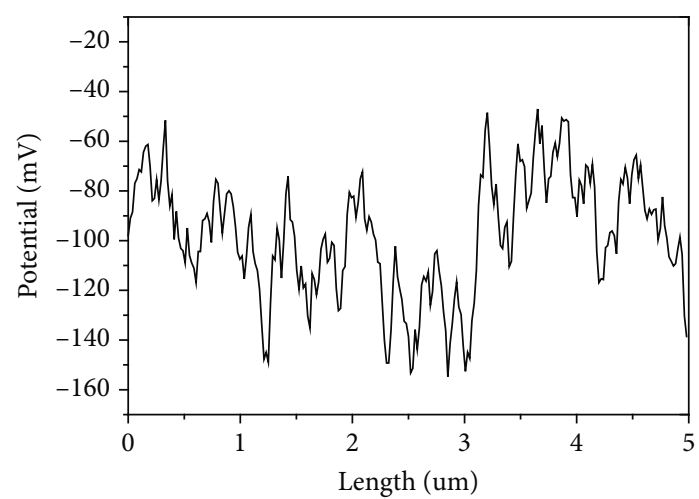

(e)

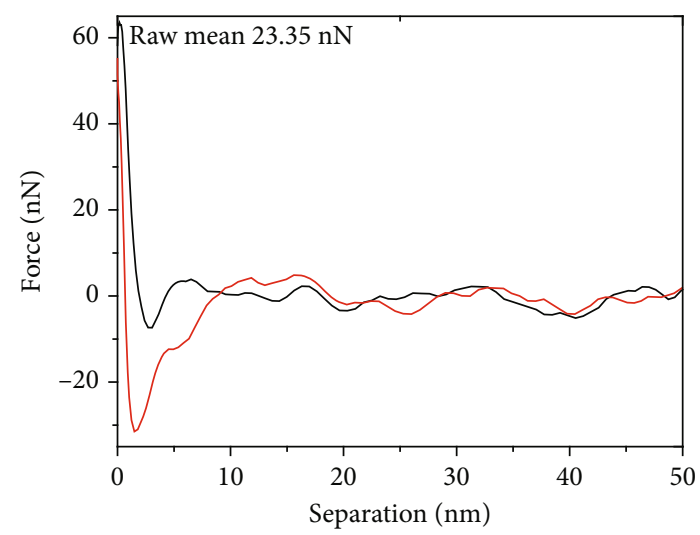

(b)

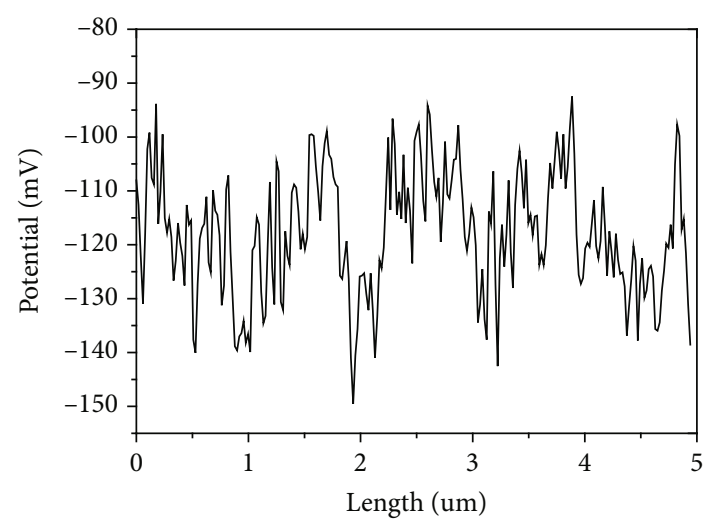

(d)

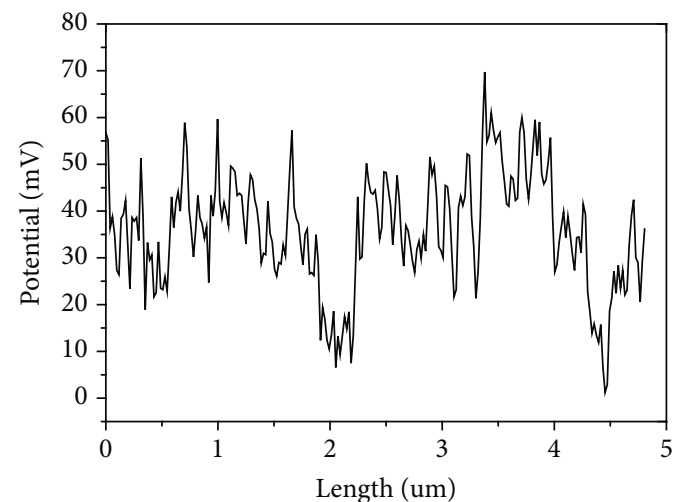

(f)

Figure 3: Continued. 


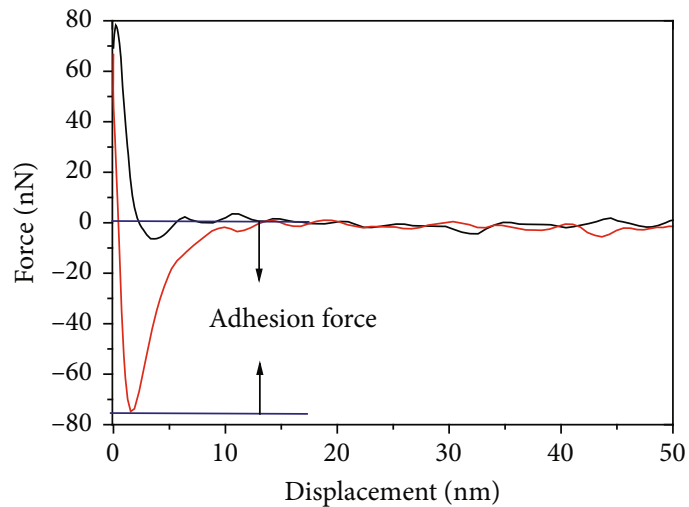

(g)

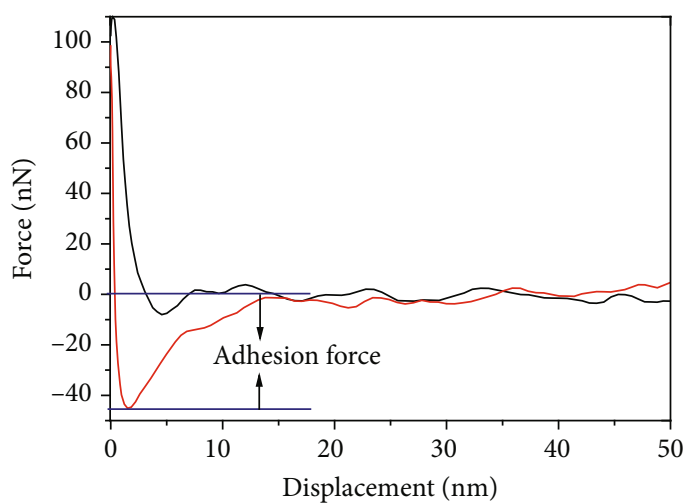

(h)

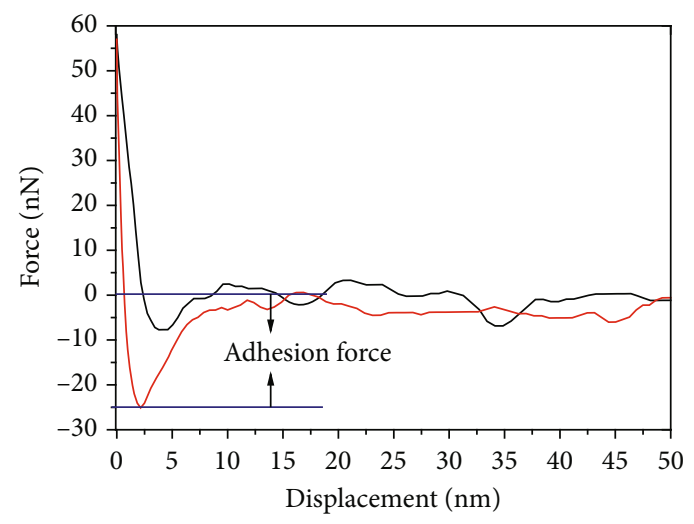

(i)

Figure 3: The SEM of AFM probe bodified $\mathrm{SiO}_{2}-\mathrm{P}_{\mathrm{Ce}-\mathrm{IL}}$ (a); the interaction between $\mathrm{S}$. mutans biofilm and $\mathrm{Ce} 6(\mathrm{~b}), \mathrm{SiO}_{2}-\mathrm{P}_{\mathrm{Ce}-\mathrm{IL}}(\mathrm{c})$; the surface potential of S. mutans biofilm (d) and treated with $\mathrm{Ce} 6(\mathrm{e}), \mathrm{SiO}_{2}-\mathrm{P}_{\mathrm{Ce} 6-\mathrm{IL}}$ (f); the adhesion of S. mutans biofilm (g) and treated with $\mathrm{Ce} 6(\mathrm{~h}), \mathrm{SiO}_{2}-\mathrm{P}_{\mathrm{Ce} \text {-IL }}$ (i).

free Ce6 (0.1 mM Ce6) using a $660 \mathrm{~nm}$ LED light $(0.5 \mathrm{~W} /$ $\mathrm{cm}^{2}$ ) for $15 \mathrm{~min}$. Each group was provided the National Institutes of Health cariogenic diet 2000 and 5\% sucrose water ad libitum. The experiment proceeded for 2 weeks; all animals were weighed weekly. At the end of the experimental period, animals were sacrificed, and the teeth were observed by SEM. Finally, the heart, liver, spleen, lung, and kidney were harvested for histological sections (H\&E staining analysis on a Leica SP8 microscope).

2.7. Cell Viability Assays. The cell viability of $\mathrm{SiO}_{2}-\mathrm{P}_{\mathrm{Ce}-\mathrm{IL}}$ was evaluated by CCK-8 assays. L929 fibroblast cells were used as model cells and seeded into 96-well plates (6000 cells per well) with $180 \mu \mathrm{L}$ of DMEM culturing medium in each well for $24 \mathrm{~h}$. $\mathrm{SiO}_{2}-\mathrm{P}_{\mathrm{Ce}-\mathrm{IL}}$ solution with concentrations from $0.2974,0.5587$, and $1.1173 \mathrm{mM}$ was added to the cells and irradiated by LED light $\left(0.5 \mathrm{~W} / \mathrm{cm}^{2}\right)$ for $15 \mathrm{~min}$. After being incubated for $48 \mathrm{~h}, 200 \mu \mathrm{L}$ of MTT solution $(0.5 \mu \mathrm{g} / \mathrm{mL})$ was added to each well and cultured for another $2 \mathrm{~h} .200 \mu \mathrm{L}$ DMSO was added and shook for $10 \mathrm{~min}$ to dissolve the crystal. Then, the absorbance was recorded at $490 \mathrm{~nm}$ by a microplate reader (model 550, BioRad).

2.8. Hemolysis Assay. The red blood cells washed with PBS until the supernatant was pellucid and was diluted to 2 vol\% by PBS. The $\mathrm{Ce} 6$ and $\mathrm{SiO}_{2}-\mathrm{P}_{\text {Ce6-IL }}(0.1 \mathrm{mM})$ were immersed into 2 vol\% red blood cell solutions $(5 \mathrm{~mL}$ for each tube) and incubated at $37^{\circ} \mathrm{C}$ for $3 \mathrm{~h}$, respectively. Then, the samples were centrifuged at $1500 \mathrm{rpm}$ for $10 \mathrm{~min}$, and the $\mathrm{OD}$ values were recorded at $545 \mathrm{~nm}$. The red blood cells treated with water as the positive control, while the red blood cells treated with PBS as negative control. The hemolysis rate was determined by the equation (2):

$$
\text { Hemolysis rate } \%=\frac{\mathrm{OD}_{\text {sample }}-\mathrm{OD}_{\text {negative control }}}{\mathrm{OD}_{\text {positive }}-\mathrm{OD}_{\text {negative control }}} \times 100 \% \text {. }
$$

Besides hemolysis rate, the major organs including the hearts, livers, spleens, lungs, and kidneys were collected and stained with H\&E for further evaluation of biocompatibility as previously reported [17].

\section{Results and Discussion}

3.1. Characterization of $\mathrm{SiO}_{2}-P_{\mathrm{Ce}-\mathrm{IL}}$. In order to strong interaction, the $8.92 \% \mathrm{Br}$ of ATRP grafted on $\mathrm{SiO}_{2}$ (Figure 2(d)). As showed in Figure 2(a), the size of $\mathrm{SiO}_{2}$ $\mathrm{P}_{\text {Ce6-IL }}$ was about $70 \mathrm{~nm}$, and the surface was more rough after initiated by $\mathrm{CuCl}$. Element analysis displayed that $\mathrm{N}$ elements of $\mathrm{P}_{\mathrm{Ce} \text {-IL }}$ were on the $\mathrm{SiO}_{2}$. The location of $\mathrm{Si}$ 
(a)
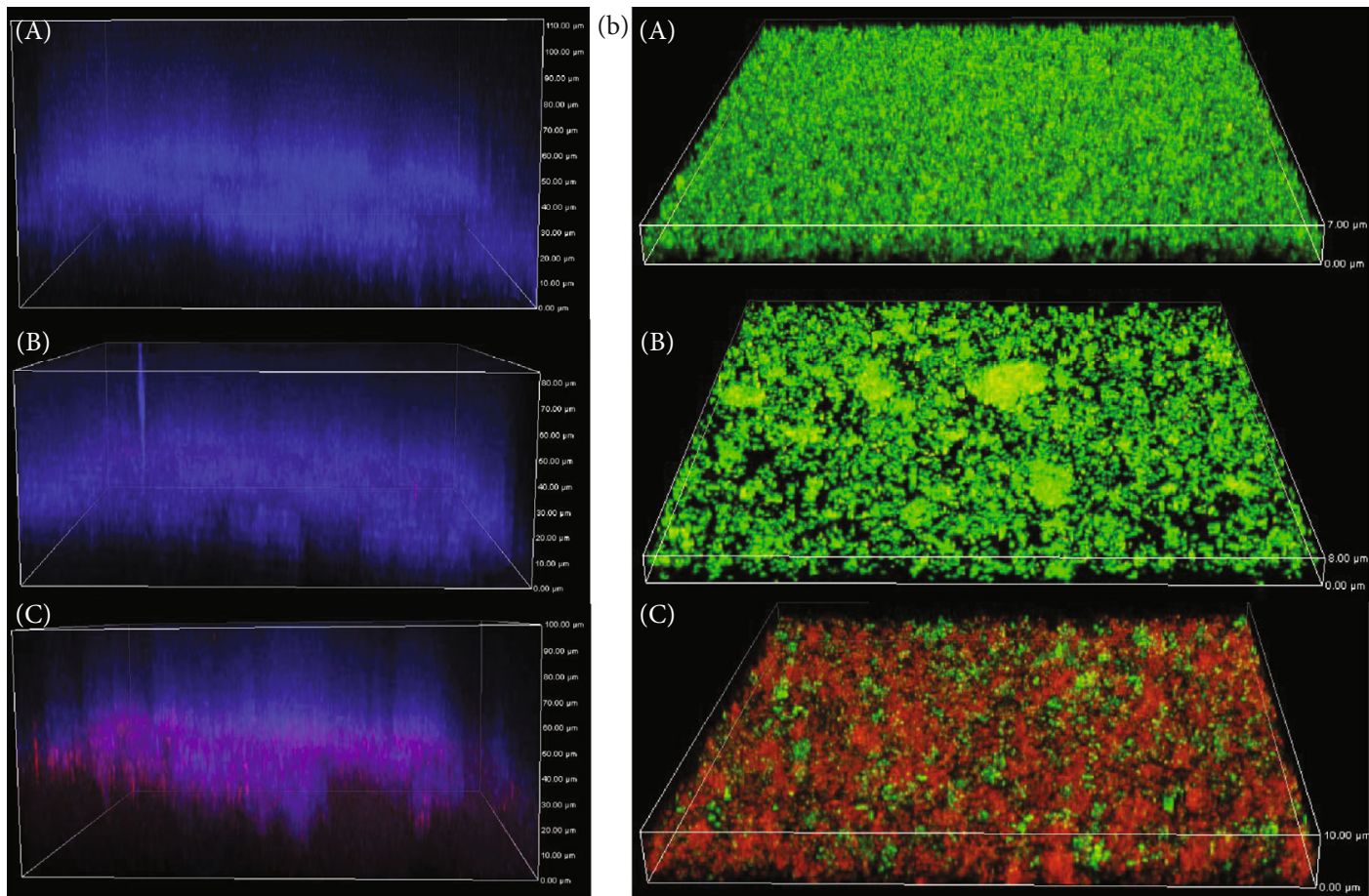

(c)
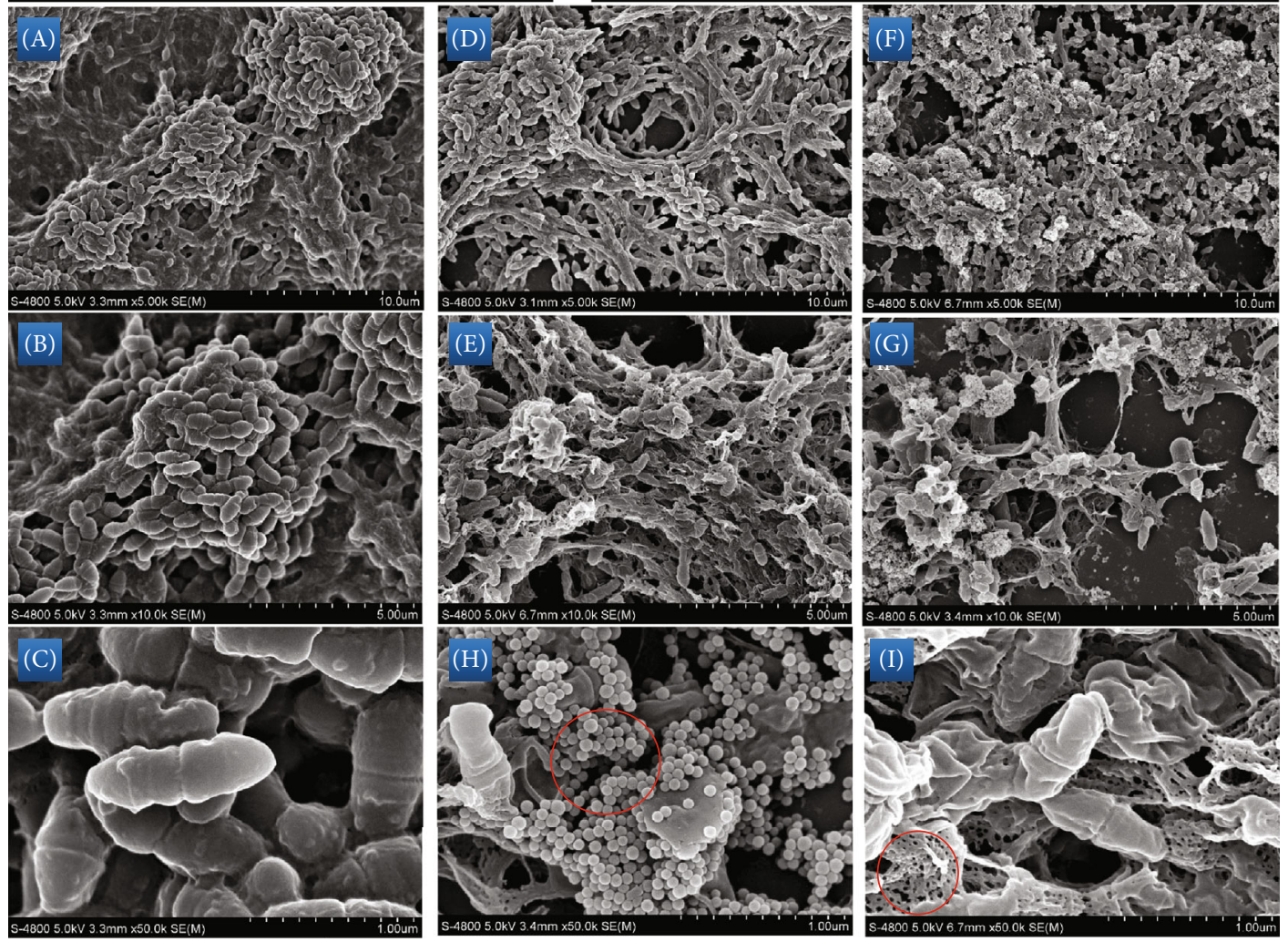

Figure 4: (a) (A) S. mutans biofilm; (B) S. mutans biofilm treated with Ce6; (C) S. mutans biofilm treated with $\mathrm{SiO}_{2}-\mathrm{P}_{\mathrm{Ce} \text {-II }}$; (b) live (green) and dead (red) results; (A) control group; (B) treated with Ce6; (C) treated with $\mathrm{SiO}_{2}-\mathrm{P}_{\mathrm{Ce}-\mathrm{IL}}$; (c) (A-C) the morphology of S. mutans biofilm; (D, E) the morphology of S. mutans biofilm treated with Ce6; (F, G) the morphology of S. mutans biofilm treated with $\mathrm{SiO}_{2}{ }^{-}$ $\mathrm{P}_{\mathrm{Ce6-IL}} ;(\mathrm{H})$ the morphology of $\mathrm{S}$. mutans biofilm combined with $\mathrm{SiO}_{2}-\mathrm{P}_{\mathrm{Ce} 6-\mathrm{IL}}$; (I) the pores in the EPS.

and $\mathrm{N}$ elements was further analyzed by the Spherical Aberration Corrected Transmission Electron Microscope (ACTEM) analysis software. The analysis results showed that the $\mathrm{N}$ element was on the surface of Si (Figure 2(b)).
These results indicated that the $\mathrm{P}_{\mathrm{Ce} \text {-IL }}$ was successful grafted on the surface of $\mathrm{SiO}_{2}$.

Because ${ }^{1} \mathrm{O}_{2}$ was a major factor in photodynamic therapy [18], the ${ }^{1} \mathrm{O}_{2}$ production of $\mathrm{SiO}_{2}-\mathrm{P}_{\text {Ce6-IL }}$ was examined 

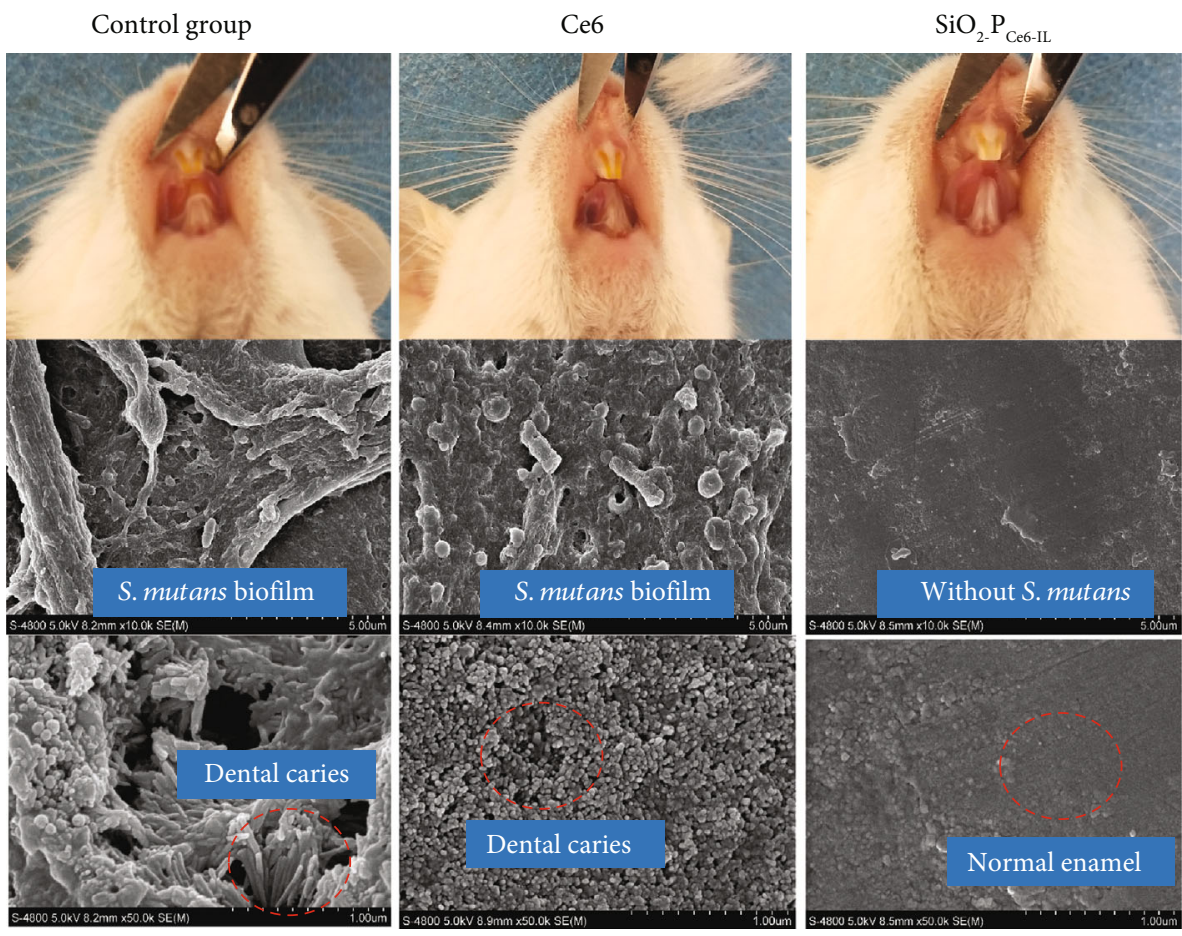

Figure 5: Tooth surface morphology with the treatment of $\mathrm{Ce} 6$ and $\mathrm{SiO}_{2}-\mathrm{P}_{\mathrm{Ce}-\mathrm{IL}}$.

by DPBF. For the reaction of DPBF with ${ }^{1} \mathrm{O}_{2}$ decreased the absorption of DPBF at $410 \mathrm{~nm}$, the consumption rate of DPBF corresponds to the ${ }^{1} \mathrm{O}_{2}$ production. Compared to the reduced absorbance of DPBF treated by Ce6 (from 3.15 to 1.75$),{ }^{14}$ the absorbance of DPBF treated by $\mathrm{SiO}_{2}-\mathrm{P}_{\mathrm{Ce}}-\mathrm{IL}$ reduced from 2.69 to 0.24 , and the consumption of DPBF was 2.45 (Figure 2(c)). The $\mathrm{SiO}_{2}-\mathrm{P}_{\mathrm{Ce}}$-IL had higher ${ }^{1} \mathrm{O}_{2}$. More ${ }^{1} \mathrm{O}_{2}$ production indicated that $\mathrm{SiO}_{2}-\mathrm{P}_{\text {Ce6-IL }}$ had strong oxidation capacity and high PACT efficacy.

3.2. Binding Ability of $\mathrm{SiO}_{2}-P_{\mathrm{Ce}-\mathrm{IL}}$ with Oral Biofilm. The Streptococcus mutans (S. mutans) is one of the primary pathogenic bacteria that cause caries. In this work, S. mutans biofilm as model was used to study antibacterial ability of $\mathrm{SiO}_{2}-\mathrm{P}_{\mathrm{Ce}}$-IL. To mimic the bacterial biofilm on the teeth, bacteria were grown for $72 \mathrm{~h}$ on hydroxyapatite disks. Due to acid microenvironment of S. mutans biofilm, the Ce6 was protonated and released; then, $\mathrm{SiO}_{2}-\mathrm{P}_{\mathrm{Ce}-\mathrm{IL}}$ changed to positive charged $\mathrm{SiO}_{2}-\mathrm{P}_{\mathrm{IL}}{ }^{+}$. The biofilm had anions such as carboxyl, phosphoryl, and glycerate at the proteins or polysaccharides would produce negatively charge [19]. The electrostatic interactions would occur between $\mathrm{SiO}_{2}-\mathrm{P}_{\mathrm{IL}}{ }^{+}$and $\mathrm{S}$. mutans biofilm. In order to detect interaction strength, the AFM was used to detect the interaction between $\mathrm{SiO}_{2}-\mathrm{P}_{\mathrm{IL}}{ }^{+}$ and S. mutans biofilm. As showed in Figure 3(a), the $\mathrm{SiO}_{2}-$ $\mathrm{P}_{\text {Ce6-IL }}$ has been successfully modified on the AFM probe. The interaction between $\mathrm{SiO}_{2}-\mathrm{P}_{\text {Ce6-IL }}$ with $\mathrm{S}$. mutans biofilm was $954.02 \mathrm{nN}$ which contributed by imidazolium cation and dodecyl in the $\mathrm{SiO}_{2}-\mathrm{P}_{\mathrm{IL}}{ }^{+}$. However, the interaction of Ce6 with S. mutans biofilm was only $23.35 \mathrm{nN}$, and this weak force was difficult to resist saliva cleaning. This strong interaction was also proved by SEM. As showed in Figure 4(c), the $\mathrm{SiO}_{2}-\mathrm{P}_{\mathrm{IL}}{ }^{+}$like multiclawed octopus and could firmly adsorb on the S. mutans biofilm (EPS). Along with massive positive charges of $\mathrm{SiO}_{2}-\mathrm{P}_{\mathrm{IL}}{ }^{+}$, the surface potential of $\mathrm{S}$. mutans biofilm changed from -117 to $35 \mathrm{mV}$, and the adhesion of S. mutans biofilm was decreased from $-76 \mathrm{nN}$ to $-25 \mathrm{nN}$. However, the adhesion of S. mutans biofilm treated by $\mathrm{Ce} 6$ alone was $-45 \mathrm{nN}$. Due to the strong adhesion, the oral biofilm infection was difficult to eradicate. So, the decreased adhesion of $\mathrm{SiO}_{2}-\mathrm{P}_{\mathrm{Ce} \text { - IL }}$ will be beneficial to eliminating biofilm infection.

3.3. Antibacterial Activity In Vitro. As a result of strong interaction, the $\mathrm{SiO}_{2}-\mathrm{P}_{\mathrm{IL}}{ }^{+}$combined with biofilm firmly and the problem of saliva cleaning was solved. But the barrier of biofilm also severely restricted the PACT efficacy against oral biofilm. As showed in Figure 4(a), the blue was S. mutans biofilm, and the red Ce6 was difficult to enter the biofilm (Figure 4(a)). Limited by lifetime and diffusion distance of ${ }^{1} \mathrm{O}_{2}$ [20], the $\mathrm{Ce} 6$ was difficult to damage protected bacteria outside biofilm. As showed in Figure 4(b), green represented live bacteria, and red represented dead bacteria. Most bacteria were alive after treated by $\mathrm{Ce} 6$ alone. So it is very important to destroy the dense structure of biofilm to improve the $\mathrm{Ce} 6$ concentration in biofilm. Compared to $\mathrm{Ce} 6, \mathrm{SiO}_{2}-\mathrm{P}_{\mathrm{Ce} \text {-IL }}$ had hydrophobic dodecyl chain which like suckers on the arm of octopus and could destroy the structure of biofilm. In order to examine the membrane breaking effect of $\mathrm{SiO}_{2}-\mathrm{P}_{\mathrm{Ce}-\mathrm{IL}}$, the morphology of $\mathrm{S}$. mutans biofilm was characterized by SEM. As showed in Figure 4(c), the pores were created in the S. mutans biofilm. Once the biofilm was broken, the Ce6 was highly concentrated in biofilm (Figure 4(a)). After illumination for $15 \mathrm{~min}$, most of S. mutans in the biofilm were killed by $\mathrm{SiO}_{2}-\mathrm{P}_{\mathrm{Ce} 6-\mathrm{IL}}$ (Figure 4(c)). The $\mathrm{SiO}_{2}-\mathrm{P}_{\mathrm{Ce} \text {-IL }}$ greatly 


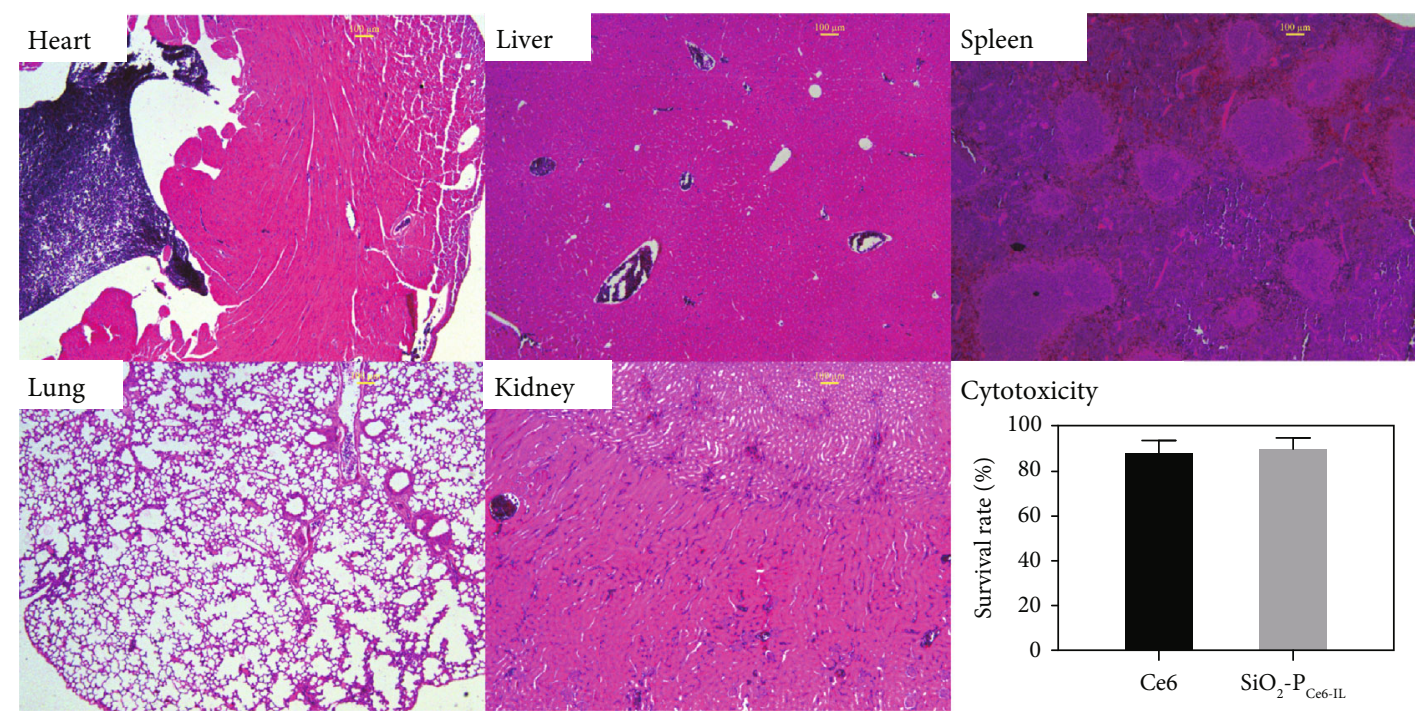

FIGURE 6: The H\&E staining of the heart, liver, spleen, lung, and kidney and cytotoxicity.

improved the PACT efficacy and could effectively eliminate of S. mutans biofilm.

3.4. In Vivo Antibiofilm Assessment. The in vitro results revealed that multiclawed $\mathrm{SiO}_{2}-\mathrm{P}_{\mathrm{Ce}-\mathrm{IL}}$ had excellent efficacy against $\mathrm{S}$. mutans biofilms. To further verify these conclusions, the in vivo experiments were designed. The infected mice were divided into three groups: treated with PBS, Ce6 with illumination for $15 \mathrm{~min}$, and $\mathrm{SiO}_{2}-\mathrm{P}_{\mathrm{Ce} \text {-IL }}$ with illumination for $15 \mathrm{~min}$. The therapeutic effects of $\mathrm{SiO}_{2}-\mathrm{P}_{\mathrm{Ce}-\mathrm{IL}}$ were evaluated by SEM. As showed in Figure 5, the treatment with $\mathrm{SiO}_{2}-\mathrm{P}_{\mathrm{Ce} 6-\mathrm{IL}}$ was very effective in preventing the development of dental caries and completely blocked extensive enamel damage. In contrast, treatment with Ce6 alone was no significant effect and resulted in enamel loss and damage, then led to dental caries.

3.5. Biocompatibility Evaluation. Although $\mathrm{SiO}_{2}-\mathrm{P}_{\mathrm{Ce}-\mathrm{IL}}$ could effective combine with oral biofilm and almost impossible to transport into the stomach from the mouth, it was important to evaluate their biocompatibility. So the cytotoxicity, hemolysis rate, and the histological section of main organs including the heart, liver, spleen and lung, and kidney were examined. The results show that no abnormal effects or damages were observed in these organs (Figure 6), and the body weights of rats treated with $\mathrm{SiO}_{2}{ }^{-}$ $\mathrm{P}_{\text {Ce6-IL }}$ were similarly to healthy rats. The hemolysis rate and cytotoxicity were $4.2 \%$ (limit of clinical hemolysis rate $<5 \%$ ) [21] and above $90 \%$ within therapeutic concentration (Figure 6). The $\mathrm{SiO}_{2}-\mathrm{P}_{\mathrm{Ce} \text {-IL }}$ was a potential safe material for clinical applications in oral biofilm infection.

\section{Conclusions}

In this work, the $\mathrm{SiO}_{2}-\mathrm{P}_{\mathrm{Ce} 6-\mathrm{IL}}$ with charge reversal and high binding ability was prepared. The potential measurements showed that $\mathrm{SiO}_{2}-\mathrm{P}_{\mathrm{Ce}-\mathrm{IL}}$ could turn into positive and combine with EPS firmly in the acidic microenvironment of oral biofilm. The morphology of S. mutans biofilm results showed that $\mathrm{SiO}_{2}-\mathrm{P}_{\mathrm{Ce}-\mathrm{IL}}$ could combine with EFS and destroy the structure of biofilm. The laser scanning confocal microscopy results found that the concentration of Ce6 in S. mutans biofilm was greatly improved, and most of bacteria in biofilm were killed. In vivo experiments showed that the $\mathrm{SiO}_{2}-\mathrm{P}_{\text {Ce6-IL }}$ was a highly desirable property for oral biofilm infection and had high quality in the prevention of dental caries. Most importantly, $\mathrm{SiO}_{2}-\mathrm{P}_{\mathrm{Ce} 6-\mathrm{IL}}$ had good biocompatibility in therapeutic effective concentrations.

\section{Data Availability}

The experimental data used to support the findings of this study are included within the article.

\section{Conflicts of Interest}

The authors declare that there is no conflict of interest regarding the publication of this paper.

\section{Authors' Contributions}

Ziyi Jiao and Yonggang Teng contributed equally to this work.

\section{Acknowledgments}

This work was supported by the National Natural Science Foundation of China (Grant Nos. 31771087 and 32171388), the Innovation Capability Support Plan of Shaanxi Province (No. 2020TD-041), and the Shaanxi Natural Science (Nos. 2021JM-238 and 2021JQ-334).

\section{References}

[1] X. Chen, E. B. Daliri, N. Kim, J. R. Kim, D. Yoo, and D. H. Oh, "Microbial etiology and prevention of dental caries: exploiting 
natural products to inhibit cariogenic biofilms," Pathogens, vol. 9, no. 7, p. 569, 2020.

[2] A. P. V. Colombo and A. C. R. Tanner, "The role of bacterial biofilms in dental caries and periodontal and peri-implant diseases: a historical perspective," Journal of Dental Research, vol. 98, no. 4, pp. 373-385, 2019.

[3] Y. Wang, S. Ma, X. Shen et al., "Oral biofilm elimination by combining iron-based nanozymes and hydrogen peroxideproducing bacteria," Biomaterials Science, vol. 8, no. 9, pp. 2447-2458, 2020.

[4] E. F. Nardini, T. S. Almeida, T. M. Yoshimura, M. S. Ribeiro, R. J. Cardoso, and A. S. Garcez, "The potential of commercially available phytotherapeutic compounds as new photosensitizers for dental antimicrobial PDT: a photochemical and photobiological in vitro study," Photodiagnosis and Photodynamic Therapy, vol. 27, pp. 248-254, 2019.

[5] R. M. Pinto, F. A. Soares, S. Reis, C. Nunes, and P. van Dijck, "Innovative strategies toward the disassembly of the EPS matrix in bacterial biofilms," Frontiers in Microbiology, vol. 11, p. 952, 2020.

[6] D. S. W. Benoit, K. R. Sims Jr., and D. Fraser, "Nanoparticles for oral biofilm treatments," ACS Nano, vol. 13, no. 5, pp. 4869-4875, 2019.

[7] L. D. Blackman, Y. Qu, P. Cass, and K. E. S. Locock, "Approaches for the inhibition and elimination of microbial biofilms using macromolecular agents," Chemical Society Reviews, vol. 50, no. 3, pp. 1587-1616, 2021.

[8] L. Karygianni, Z. Ren, H. Koo, and T. Thurnheer, "Biofilm matrixome: extracellular components in structured microbial communities," Trends in Microbiology, vol. 28, no. 8, pp. 668-681, 2020.

[9] T. P. Cavazana, J. P. Pessan, T. Y. Hosida et al., "Effects of sodium trimetaphosphate, associated or not with fluoride, on the composition and $\mathrm{pH}$ of mixed biofilms, before and after exposure to sucrose," Caries Research, vol. 54, no. 4, pp. 358368, 2020.

[10] L. Chen, Y. Yang, P. Zhang, S. Wang, J. F. Xu, and X. Zhang, "Degradable supramolecular photodynamic polymer materials for biofilm elimination," ACS Applied Bio Materials, vol. 2, no. 7, pp. 2920-2926, 2019.

[11] S. T. Wang, Y. Fang, Z. Q. Zhang, Q. Jin, and J. Ji, "Bacterial infection microenvironment sensitive prodrug micelles with enhanced photodynamic activities for infection control," Colloid and Interface Science Communications, vol. 40, article 100354, 2021.

[12] C. Takahashi, Y. Hattori, S. Yagi et al., "Optimization of ionic liquid-incorporated PLGA nanoparticles for treatment of biofilm infections," Materials Science and Engineering, vol. 97, pp. 78-83, 2019.

[13] C. Zhou, C. J. Sheng, L. L. Gao, J. Guo, P. Li, and B. Liu, "Engineering poly(ionic liquid) semi-IPN hydrogels with fast antibacterial and anti-inflammatory properties for wound healing," Chemical Engineering Journal, vol. 413, article 127429, 2021.

[14] C. L. Wang, P. Chen, Y. B. Qiao et al., "pH responsive superporogen combined with PDT based on poly Ce6 ionic liquid grafted on SiO2for combating MRSA biofilm infection," Theranostics, vol. 10, no. 11, pp. 4795-4808, 2020.

[15] F. Ostadhossein, S. K. Misra, I. Tripathi et al., "Dual purpose hafnium oxide nanoparticles offer imaging Streptococcus mutans dental biofilm and fight it In vivo via a drug free approach," Biomaterials, vol. 181, pp. 252-267, 2018.

[16] M. Y. Zhang, G. Chen, M. Lei, J. Lei, D. Li, and H. Zheng, "A $\mathrm{pH}$-sensitive oxidized-dextran based double drug-loaded hydrogel with high antibacterial properties," International Journal of Biological Macromolecules, vol. 182, pp. 385-393, 2021.

[17] C. R. Yan, C. L. Wang, T. T. Hou et al., "Lasting tracking and rapid discrimination of live gram-positive bacteria by peptidoglycan-targeting carbon quantum dots," ACS Applied Materials \& Interfaces, vol. 13, no. 1, pp. 1277-1287, 2021.

[18] Y. H. Ong, A. Dimofte, M. M. Kim et al., "Reactive oxygen species explicit dosimetry for photofrin-mediated pleural photodynamic therapy," Photochemistry and Photobiology, vol. 96, no. 2, pp. 340-348, 2020.

[19] B. Ran, Y. Y. Yuan, W. X. Xia et al., “A photo-sensitizable phage for multidrug-resistantAcinetobacter baumanniitherapy and biofilm ablation," Chemical Science, vol. 12, no. 3, pp. 1054-1061, 2021.

[20] Y. H. Li, J. Q. Chu, D. X. Wang, L. Zhu, and D. Kong, "DNA nanolantern as biocompatible drug carrier for simple preparation of a porphyrin/G-quadruplex nanocomposite photosensitizer with high photodynamic efficacy," Materials Chemistry Frontiers, vol. 5, no. 7, pp. 3139-3148, 2021.

[21] H. H. Xu, Z. H. Jiang, C. S. Huang et al., "Global metabolomic and lipidomic analysis reveals the potential mechanisms of hemolysis effect of Ophiopogonin D and Ophiopogonin D' in vivo," Chinese Medicine, vol. 16, no. 3, 2021. 